Quim. Nova, Vol. 36, No. 7, 1052-1056, 2013

\title{
DEVELOPMENT OF A SIMPLE ANALYTICAL METHOD FOR DETERMINING TRIHALOMETHANES IN BEER USING A HEADSPACE SOLID-PHASE MICROEXTRACTION TECHNIQUE
}

\author{
Marcel Silveira dos Santos* \\ Departamento de Engenharia Química, Universidade Federal de Santa Catarina, Centro Tecnológico, Campus Universitário, \\ Córrego Grande, 88040-900 Florianópolis - SC, Brasil \\ Eduardo Carasek \\ Departamento de Química, Universidade Federal de Santa Catarina, Campus Universitário, Trindade, 88040-900 Florianópolis \\ - SC, Brasil \\ Recebido em 11/2/13; aceito em 14/3/13; publicado na web em 13/6/13
}

\begin{abstract}
We developed a simple, rapid, and solventless method for analyzing trihalomethanes in beer samples using headspace solid-phase microextraction. The effects of varying experimental parameters, such as extraction temperature and time, addition of sodium chloride, and agitation speed, on extraction yield were studied using a univariate experimental design. Limits of detection between 0.22 and $0.46 \mu \mathrm{g} \mathrm{L}^{-1}$ and wide linear ranges were achieved for trihalomethanes. We measured the trihalomethane recoveries and precision (as the standard deviation of repeat measurements) and demonstrated the applicability of the proposed method by analyzing 32 beer samples.
\end{abstract}

Keywords: THMs; beer; SPME.

\section{INTRODUCTION}

Water is a vital ingredient in beer. It is essential at various stages of the brewing process and is responsible for different flavor and color characteristics in the finished beer. More than 800 organic compounds are used in brewing this millenarian beverage. Knowing that water quality plays an important role in beer production, breweries invest in improving the quality of their water supplies and in disinfection treatments, such as ozone treatment, which does not generate potentially harmful residues. However, chlorination is the most widely used water disinfection process in Brazil. ${ }^{1}$

Chlorine treatment started to be used for disinfecting drinking water in the early 1900s, and it has dramatically reduced the number of incidences of waterborne diseases and has improved the overall quality of life for many people. ${ }^{2}$ However, chlorine treatment leads to many disinfection byproducts that are considered to be carcinogens. ${ }^{3,4} \mathrm{~A}$ complex mixture of chlorination disinfection byproducts (CDBPs) is formed when water containing natural organic matter is chlorinated, and more than 700 different CDBPs have been identified. ${ }^{5}$ Trihalomethanes (THMs) and haloacetic acids are the most important groups of CDBPs, and haloacetonitriles, haloketones, and chloropicrin are also produced. THMs include chloroform, bromodichloromethane, dibromochloromethane, and bromoform, and the sum of these four substances is called the total THMs (TTHMs). ${ }^{6}$ Some of these chlorination byproducts, such as chloroform and bromodichloromethane, which are the first and second most dominant trihalomethane species, respectively, are known to be animal carcinogens, and their potential ability to increase cancer risk in humans is under active investigation. ${ }^{7-9}$

The maximum contaminant level for TTHMs in drinking water has recently been decreased to $80 \mu \mathrm{g} \mathrm{L}^{-1}$ because of a two-stage disinfectant/disinfection byproduct rule implemented by the United States Environmental Protection Agency (US EPA). ${ }^{10,11}$ Some European countries have even stricter laws on the presence of THMs in water, and the maximum trihalomethane concentrations allowed

*e-mail: marcelsilveira_qmc@hotmail.com by Germany and Switzerland are 10 and $25 \mu \mathrm{g} \mathrm{L}^{-1}$, respectively, in drinking water. ${ }^{12,13}$ Studies of mammals have shown that THMs affect the central nervous system and cause hepatotoxicity, reproductive toxicity, nephrotoxicity, and renal toxicity. ${ }^{14}$ Chloroform is included in the top 20 list of toxic substances by Agency for Toxic Substances and Disease Registry. ${ }^{15}$ The adverse health effects of chloroform have been studied extensively, and it is cytotoxic to liver, kidney, and nasal epithelium. ${ }^{16}$ Human exposure to chloroform may principally occur through inhalation, ingestion, and dermal contact. ${ }^{17}$ Brominated THMs may pose a greater risk than chloroform to human health because they have been found to be more toxic than chloroform to rodents. Bromodichloroform exposure through drinking water has been shown to cause more incidences of preneoplastic aberrant crypt foci in rat colons than caused by chloroform exposure. ${ }^{18,19}$

Different analytical methods using gas chromatography have been reported for determining THMs in drinking water. The low concentrations of THMs in water samples mean that a concentration step is required before gas chromatographic analysis, and because of their volatilities, dynamic headspace techniques (purge and trap), static headspace techniques, and solid-phase microextraction (SPME) techniques are most commonly used to achieve this. ${ }^{20-23}$ SPME techniques combine analyte isolation from the sample matrix, analyte concentration, and introduction of analytes into the gas chromatograph in a single process. Headspace-SPME (HS-SPME) techniques are generally more sensitive than static headspace techniques because partitioning the analyte into a fiber from the gas, similar to HS-SPME, leads to the analytes being concentrated. Detection limits for SPME methods have been achieved that are comparable to or lower than those for purge and trap methods. SPME also offers advantages over other methods, such as its operational simplicity and efficiency. ${ }^{24-26}$

This study aims to explore the potential for using SPME for quantifying THMs in commercially available beer in the city of Florianópolis (the capital of the state of Santa Catarina, Brazil). We used a univariate method to optimize the parameters that affect THM extraction using SPME fibers. The parameters studied were the extraction temperature and time, agitation speed, amount of $\mathrm{NaCl}$ added, and headspace volume. The optimized method was 
validated by determining the limits of detection and quantification, linearity and linear range, repeatability, and accuracy. To the best of our knowledge, this is the first time that SPME has been used to quantify THMs in beer.

\section{EXPERIMENTAL}

\section{Reagents and materials}

Individual stock standard solutions of chloroform (Tedia, Fairfield, OH, USA), dichlorobromomethane, chlorodibromomethane (SigmaAldrich, Milwaukee, USA), and bromoform (Synth, Diadema, Brazil) were prepared in methanol (Supelco, Bellefonte, PA, USA) to give solutions of 4700, 2500, 2500, and $5080 \mathrm{mg} \mathrm{L}^{-1}$, respectively. Intermediate standard solutions of $100,25,2$, and $0.1 \mathrm{mg} \mathrm{L}^{-1}$ of each compound were prepared in methanol by diluting the stock standard solutions. Intermediate standard solutions of $100 \mathrm{mg} \mathrm{L}^{-1}$ were also prepared from $2000 \mathrm{mg} \mathrm{L}^{-1}$ stock standard solutions of dichloromethane and diiodomethane (Sigma-Aldrich) in methanol, and these compounds were used as internal standards. All standard solutions were stored at $0{ }^{\circ} \mathrm{C}$. Sodium chloride (Nuclear, Diadema, Brazil) was used to modify the ionic strength of the samples. A $6 \mathrm{~mol} \mathrm{~L}^{-1}$ ammonium hydroxide (Nuclear) solution was prepared in mineral water to neutralize the carbonic acid (pKa 6.1) in the samples to bring them to $\mathrm{pH}$ 6.1. Mineral water was used for dilutions because we found traces of THMs in distilled water and ultra pure water. Other authors have reported the presence of THMs, especially chloroform, in all aqueous matrices and even in the air. ${ }^{27}$ Because of this, mineral water was also used in the standards for constructing the external calibration curve.

\section{Instruments}

Separation of the analytes was achieved using a Shimadzu GC-14B gas chromatograph (Shimadzu, Kyoto, Japan), equipped with a split/splitless injector, an electron capture detector (ECD), and an Rtx-WAX capillary column (Restek, Bellefonte, PA, USA, $30 \mathrm{~m}$ long, $0.25 \mathrm{~mm}$ id, $0.25 \mu \mathrm{m}$ film thickness). Ultrapure nitrogen was used as the carrier gas and the make-up gas at 1.0 and $48 \mathrm{~mL} \mathrm{~min}^{-1}$, respectively. The split sample injection ratio was 1:120; the injector temperature was $280{ }^{\circ} \mathrm{C}$, except for analyses using CW-DVB fibers, for which the manufacturer's recommended maximum temperature of $260{ }^{\circ} \mathrm{C}$ was used. The oven temperature program was $40^{\circ} \mathrm{C}$ for 2 min, increased at $8{ }^{\circ} \mathrm{C} \min ^{-1}$ to $80{ }^{\circ} \mathrm{C}$, then increased at $20{ }^{\circ} \mathrm{C} \mathrm{min}^{-1}$ to $180^{\circ} \mathrm{C}$, which was held for $1 \mathrm{~min}$. The detector temperature was $260{ }^{\circ} \mathrm{C}$. The total chromatographic run time was $12 \mathrm{~min}$.

The identities of the THMs in the samples were confirmed using a Shimadzu GC-MS-QP2010 Plus spectrometer in electron impact mode, with an electron energy of $70 \mathrm{eV}$. The quadrupole, ion source, and transfer line temperatures were 200,200 , and $280{ }^{\circ} \mathrm{C}$, respectively. The oven temperature program was $40^{\circ} \mathrm{C}$ for $4 \mathrm{~min}$, increased at $5^{\circ} \mathrm{C} \mathrm{min}-1$ to $80{ }^{\circ} \mathrm{C}$, then increased at $20^{\circ} \mathrm{C} \mathrm{min}^{-1}$ to $180{ }^{\circ} \mathrm{C}$, and splitless injection mode was used. The analytical column was an Rtx-5MS column (Restek, Bellefonte, PA, USA) and the carrier gas was helium, at $1 \mathrm{~mL} \mathrm{~min}^{-1}$. The mass spectrum acquisition range was $m / z$ 35-400, and analytes were identified from their fragmentation patterns using the NIST Mass Spectral Search Program 05 (NIST, Washington, D.C., USA).

\section{Sample collection and solid-phase microextraction procedure}

Beer samples were collected from supermarkets in Florianópolis. Several brands of pilsen and dark beers, in different packaging types (glass bottles and cans), were selected. All samples were stored at $0{ }^{\circ} \mathrm{C}$.
SPME extractions were performed using carboxen-polydimethylsiloxane (CAR-PDMS) fibers. The fibers were conditioned at $300{ }^{\circ} \mathrm{C}$ for $1 \mathrm{~h}$ before use, and blank desorptions were carried out periodically. Each sample $(20 \mathrm{~mL})$ was transferred into a vial $(40 \mathrm{~mL})$ containing $20 \%(\mathrm{w} / \mathrm{v})$ sodium chloride and $130 \mu \mathrm{L}$ of $6 \mathrm{~mol} \mathrm{~L}^{-1}$ $\mathrm{NH}_{4} \mathrm{OH}$. Dichloromethane and diiodomethane internal standards at 50 and $25 \mu \mathrm{g} \mathrm{L}^{-1}$, respectively, were added.

The incubation and extraction temperature was $30^{\circ} \mathrm{C}$, and the samples were equilibrated for $8 \mathrm{~min}$ before extraction. The magnetic stirring speed was $1000 \mathrm{rpm}$. The fiber, attached to a syringe, was placed in the sample headspace for $15 \mathrm{~min}$, drawn back into the needle, and transferred without delay $(<5 \mathrm{~s})$ into the GC injection port, where it was desorbed for $3 \mathrm{~min}$ at $280{ }^{\circ} \mathrm{C}$. All analyses were performed in triplicate.

\section{Optimization of the trihalomethane extraction method variables}

A method previously developed for analyzing soft drink samples by Santos, Martendal, and Carasek ${ }^{28}$ was used to analyze the beer samples. The effects of varying five variables, extraction temperature, extraction time, headspace volume, the effect of salt, and the stirring speed, were studied on THM extraction. Extraction temperatures between 10 and $80^{\circ} \mathrm{C}$ and headspace volumes between 15 and $39 \mathrm{~mL}$ (i.e., using sample volumes of $1-25 \mathrm{~mL}$ in $40 \mathrm{~mL}$ vials) were tested. An appropriate volume of an $\mathrm{NH}_{4} \mathrm{OH}$ solution was added to each sample to bring the sample to $\mathrm{pH} 6.1 \mathrm{NaCl}$ was added between 0 and $6 \mathrm{~g}(0 \%-30 \% \mathrm{w} / \mathrm{v})$ to each sample, and stirring speeds of $0-1000$ $\mathrm{rpm}$ and stirring times of $1-45 \mathrm{~min}$ were tested. THMs of $10 \mu \mathrm{g} \mathrm{L}^{-1}$ were added to each sample for the optimization tests, and each experiment was carried out in triplicate. The average peak height for each compound was used as the test response.

The optimized parameters were $20 \mathrm{~mL}$ of beer sample, with $150 \mu \mathrm{L}$ of $6 \mathrm{~mol} \mathrm{~L}^{-1} \mathrm{NH}_{4} \mathrm{OH}$, extraction at $30{ }^{\circ} \mathrm{C}$ for $10 \mathrm{~min}$, and stirred at $500 \mathrm{rpm}$.

\section{Analytical performance}

The linear ranges of the optimized HS-SPME GC-ECD method for the analytes were evaluated by constructing calibration curves of the analyte peak height relative to the internal standard (dichloromethane for $\mathrm{CHCl}_{3}, \mathrm{CHCl}_{2} \mathrm{Br}$, and $\mathrm{CHClBr}_{2}$; diiodomethane for $\mathrm{CHBr}_{3}$ ) against the analyte concentration using standards prepared in mineral water (free of THMs)

\section{RESULTS AND DISCUSSION}

\section{Effect of carbon dioxide on trihalomethane extraction}

The effect of $\mathrm{CO}_{2}$ on the extraction of THMs from beer was studied by comparing the effect of adding or excluding $130 \mu \mathrm{L}$ of $6 \mathrm{~mol} \mathrm{~L}-1$ $\mathrm{NH}_{4} \mathrm{OH}$ to a $20 \mathrm{~mL}$ beer sample on the extraction efficiency. The best extraction efficiency was found when $\mathrm{NH}_{4} \mathrm{OH}$ was added, up to $35 \%$ more THMs being extracted than without $\mathrm{NH}_{4} \mathrm{OH}$. The analytes were most effectively released from the aqueous phase to the gas phase when the headspace was close to atmospheric pressure, and, with the beer samples, the transfer of analytes between the two phases most effectively occurred when $\mathrm{CO}_{2}$ was not at high concentrations in the headspace.

\section{The choice of fiber}

There are reports in the literature of PDMS, ${ }^{29}$ carbowax-divinylbenzene (CW-DVB), ${ }^{30}$ PDMS-DVB, ${ }^{31}$ and DVB-CAR-PDMS 
fibers $^{32}$ being used to extract THMs from water. However, many authors have concluded that the CAR-PDMS fiber gives the best extraction efficiency, ${ }^{33-36}$ which can be attributed to the porous carboxen phase that is able to capture small analytes (with between two and twelve carbon atoms). Therefore, the CAR-PDMS fiber was selected for the optimized method.

\section{Effects of temperature, time, headspace volume, salting out, and stirring speed on THM extraction}

The time needed to reach equilibrium between the sample and the fiber decreased as the extraction temperature was increased, because of the increased diffusion of the analytes to the fiber surface. However, the sorption process is exothermic; thus, high extraction temperatures can lead to lower partition coefficients, decreasing the mass of analytes extracted at equilibrium. As can be seen in Figure 1, the best extraction efficiencies were found at $20{ }^{\circ} \mathrm{C}$ for $\mathrm{CHCl}_{3}, 30{ }^{\circ} \mathrm{C}$ for $\mathrm{CHCl}_{2} \mathrm{Br}$, and $50{ }^{\circ} \mathrm{C}$ for $\mathrm{CHClBr}_{2}$, and similar extraction efficiencies were found for $\mathrm{CHBr}_{3}$ between 30 and $60^{\circ} \mathrm{C}$. The THM extraction efficiency rapidly decreased above $60{ }^{\circ} \mathrm{C}$. An extraction temperature of $30{ }^{\circ} \mathrm{C}$ was, therefore, selected as being the optimum for extracting all analytes.

The theoretical aspects of using SPMEs dictate that the volume of the gaseous phase should be minimized to achieve the best sensitivity from headspace extraction. As can be seen in Figure 1, the best extraction efficiencies for all of the THMs were found using a $20 \mathrm{~mL}$ headspace volume (i.e., a sample volume of $20 \mathrm{~mL}$ ). The THMs were all extracted at similar efficiencies at each headspace volume, and the efficiencies generally increased as the headspace increased from 1 to $20 \mathrm{~mL}$, although using a $15 \mathrm{~mL}$ headspace gave a lower extraction efficiency. The low extraction efficiency using a $15 \mathrm{~mL}$ headspace was probably caused by insufficient sample agitation in this sample. Using a headspace volume of $15 \mathrm{~mL}$ or less in a $40 \mathrm{~mL}$ vial is not appropriate because the fiber can accidentally come into contact with the solution. A headspace volume of $20 \mathrm{~mL}$ was, therefore, used in the optimized method.

Adding salt increases the ionic strength of a solution, changing the vapor pressure, viscosity, solubilities of solutes, density, and surface tension, and resulting in altered liquid/vapor equilibria of the analytes in the system. ${ }^{35}$ As can be seen in Figure 1, adding $\mathrm{NaCl}$ led to improvements in the extraction efficiencies of each THM. No significant differences were seen between the extraction efficiencies obtained when 4,5 , or $6 \mathrm{~g}$ of $\mathrm{NaCl}$ was added.

Chloroform was least affected by adding $\mathrm{NaCl}$ probably because it is the most volatile of the THMs studied. An amount of $4 \mathrm{~g}$ of $\mathrm{NaCl}$
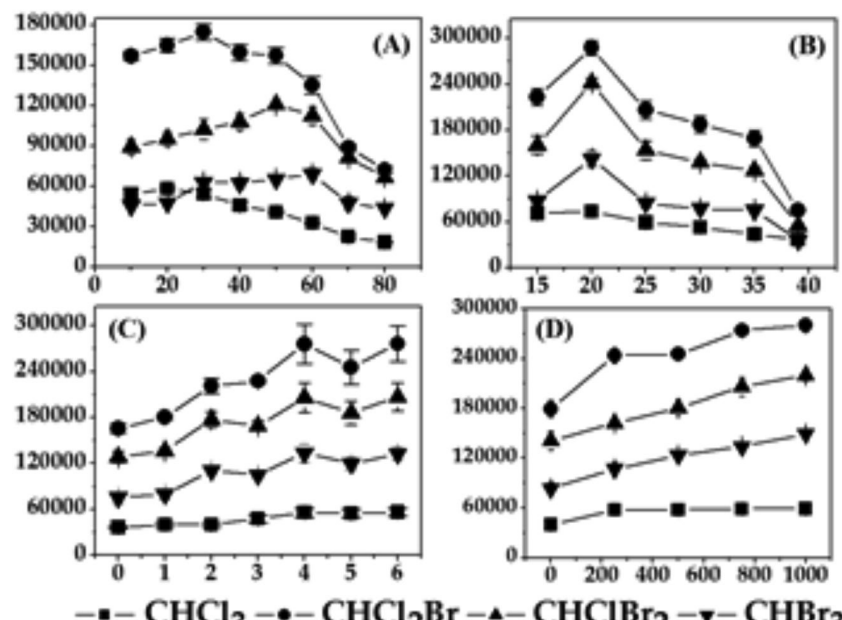

Figure 1. Results of studies of variables affecting the extraction of THMs was chosen as the optimum for the method.

In general, more agitation leads to faster mass transfer from the aqueous phase to the headspace. As is shown in Figure 1, the THM extraction efficiencies increased with magnetic stirring speed. This effect quickly reached a plateau for chloroform and was most pronounced for $\mathrm{CHCl}_{2} \mathrm{Br}$ and $\mathrm{CHClBr}_{2}$. A stirring speed of $1000 \mathrm{rpm}$ was selected for the optimized method.

Equilibria were achieved by $10 \mathrm{~min}$ for $\mathrm{CHCl}_{2} \mathrm{Br}, \mathrm{CHClBr}_{2}$, and $\mathrm{CHBr}_{3}$, and another $5 \mathrm{~min}$ was required for chloroform to reach equilibrium. The differences between the molecular weights of the analytes were not significant to cause large differences in the times taken to reach equilibrium. An extraction time of $15 \mathrm{~min}$ was selected for the optimized method.

\section{Analytical performance}

Recoveries of the analytes using the optimized method were studied, and the recoveries of the internal standards and THMs are compared in Table 1.

Table 1. Recoveries and correlation coefficients of each THM with the respective internal standard

\begin{tabular}{ccccc}
\hline \multirow{2}{*}{ Compounds s } & \multicolumn{2}{c}{ Dichloromethane } & \multicolumn{2}{c}{ Diiodomethane } \\
\cline { 2 - 5 } & Recovery, \% & R & Recovery, \% & R \\
\hline $\mathrm{CHCl}_{3}$ & $99.2^{\mathrm{a}}-97.2^{\mathrm{b}}$ & 0.999 & $87.1^{\mathrm{a}}-82.5^{\mathrm{b}}$ & 0.992 \\
$\mathrm{CHCl}_{2} \mathrm{Br}$ & $96.2-96.1$ & 0.999 & $89.1-86.9$ & 0.994 \\
$\mathrm{CHClBr}_{2}$ & $95.3-98.6$ & 0.999 & $94.7-99.2$ & 0.995 \\
$\mathrm{CHBr}_{3}$ & $89.2-86.7$ & 0.995 & $91.5-89.4$ & 0.999 \\
\hline
\end{tabular}

${ }^{\mathrm{a}} 15 \mu \mathrm{g} \mathrm{L} \mathrm{L}^{-1}$. ${ }^{\mathrm{b}} 35 \mu \mathrm{g} \mathrm{L} \mathrm{L}^{-1}$

The linear range for each of the THMs was $0.05-45 \mu \mathrm{g} \mathrm{L}^{-1}(n=$ $6)$. The limit of detection was defined as three times the standard deviation of the linear coefficient divided by the slope of the calibration curve, and the limits of detection for the THMs are shown in Table 2.

Table 2. Linear working range, correlation coefficients and limits of detection (LOD) for the proposed method for determination of THMs in beer samples

\begin{tabular}{cccc}
\hline Compounds & $\begin{array}{c}\text { Linear range } \\
\left(\mu \mathrm{g} \mathrm{L}^{-1}\right)\end{array}$ & $\begin{array}{c}\mathrm{LOD}^{\mathrm{a}} \\
\left(\mu \mathrm{g} \mathrm{L}^{-1}\right)\end{array}$ & $\mathrm{R}^{\mathrm{b}}$ \\
\hline $\mathrm{CHCl}_{3}$ & $0.5-45$ & 0.46 & 0.999 \\
$\mathrm{CHCl}_{2} \mathrm{Br}$ & $0.5-45$ & 0.22 & 0.999 \\
$\mathrm{CHClBr}_{2}$ & $0.5-45$ & 0.36 & 0.999 \\
$\mathrm{CHBr}_{3}$ & $0.5-45$ & 0.29 & 0.999 \\
\hline
\end{tabular}

${ }^{\mathrm{a}}$ limit of detection; ${ }^{\mathrm{b}}$ correlation coefficient.

The proposed method allowed $\mathrm{CHCl}_{3}, \mathrm{CHCl}_{2} \mathrm{Br}, \mathrm{CHClBr}_{2}$, and $\mathrm{CHBr}_{3}$ to be detected at concentrations around 174, 364, 167, and 275 times lower, respectively, than their maximum permissible concentrations in drinking water, as set by the US EPA. Calibration curves for standards prepared in two types of beer (pilsen and dark beer) were plotted to evaluate any matrix effects (Table 3 ). We examined differences in the relative sensitivities of the calibrations using mineral water and the two types of beer, and found that the pilsen beer had no significant matrix effect on the extraction efficiency of the proposed method. However, the dark beer did not give satisfactory relative sensitivities. Diluting a sample can minimize or solve matrix interferences and allow the quantification of analytes. Diluting the dark beer four fold, by adding $5 \mathrm{~mL}$ of beer to $15 \mathrm{~mL}$ water, gave adequate relative sensitivities for the THMs and allowed the external calibration curves to be used for quantitative analysis.

The method gave satisfactory precision, which was assessed from 
Table 3. Relative sensitivities between the calibration curve of mineral water and beer samples

\begin{tabular}{ccccc}
\hline \multirow{2}{*}{ Samples } & \multicolumn{4}{c}{ Relative Sensitivity (\%) } \\
\cline { 2 - 5 } & $\mathrm{CHCl}_{3}$ & $\mathrm{CHCl}_{2} \mathrm{Br}$ & $\mathrm{CHClBr}_{2}$ & $\mathrm{CHBr}_{3}$ \\
\hline $\mathrm{A}^{\mathrm{a}}$ & 85.8 & 88.6 & 96.2 & 108.4 \\
$\mathrm{~B}^{\mathrm{b}}$ & 90.8 & 96.2 & 85.1 & 91.1 \\
\hline
\end{tabular}

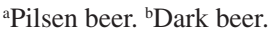

the relative standard deviations (RSDs; $n=6$ ) of spiked solution analyses. Pilsen spiked with 1,15 , and $35 \mu \mathrm{g} \mathrm{L}{ }^{-1}$ of each THM gave RSDs of $6.6 \%-13.1 \%, 4.0 \%-5.2 \%$, and $1.4 \%-2.1 \%$, respectively, and dark beer spiked in the same way gave RSDs of 7.1\%-10.2\%, $5.1 \%-5.9 \%$, and $2.2 \%-3.9 \%$, respectively.

\section{Applying the method to beer samples}

The proposed method was used to analyze 32 beers, including beers of two types, in different types of packaging, and of different

Table 4. Concentrations of THMs found in beer samples. Samples without designations represent beers with can packaging

\begin{tabular}{|c|c|c|c|c|}
\hline \multirow{2}{*}{ Samples } & \multicolumn{4}{|c|}{ Found concentrations $\pm \mathrm{SD}\left(\mu \mathrm{g} \mathrm{L}^{-1}\right)$} \\
\hline & $\mathrm{CHCl}_{3}$ & $\mathrm{CHCl}_{2} \mathrm{Br}$ & $\mathrm{CHClBr}_{2}$ & $\mathrm{CHBr}_{3}$ \\
\hline \multicolumn{5}{|l|}{ Type pilsen } \\
\hline A & $2.00 \pm 0.04$ & $0.28 \pm 0.10$ & $<\mathrm{LOD}$ & $<\mathrm{LOD}$ \\
\hline$A^{*}$ & $1.47 \pm 0.04$ & $0.27 \pm 0.04$ & $0.73 \pm 0.10$ & $<\mathrm{LOD}$ \\
\hline B & $1.11 \pm 0.05$ & $0.27 \pm 0.10$ & $<\mathrm{LOD}$ & $<\mathrm{LOD}$ \\
\hline $\mathrm{B} *$ & $2.43 \pm 0.30$ & $0.34 \pm 0.02$ & $<\mathrm{LOD}$ & $<\mathrm{LOD}$ \\
\hline $\mathrm{C}$ & $1.00 \pm 0.07$ & $0.56 \pm 0.10$ & $<\mathrm{LOD}$ & $<\mathrm{LOD}$ \\
\hline $\mathrm{C}^{*}$ & $2.43 \pm 0.30$ & $0.31 \pm 0.0$ & $<\mathrm{LOD}$ & $<\mathrm{LOD}$ \\
\hline $\mathrm{D}$ & $0.70 \pm 0.04$ & $0.26 \pm 0.01$ & $<\mathrm{LOD}$ & $<\mathrm{LOD}$ \\
\hline$D^{*}$ & $1.33 \pm 0.20$ & $<\mathrm{LOD}$ & $<\mathrm{LOD}$ & $<\mathrm{LOD}$ \\
\hline $\mathrm{E}$ & $0.81 \pm 0.08$ & $<\mathrm{LOD}$ & $0.37 \pm 0.06$ & $<\mathrm{LOD}$ \\
\hline $\mathrm{E}^{*}$ & $1.20 \pm 0.10$ & $<\mathrm{LOD}$ & $<\mathrm{LOD}$ & $<\mathrm{LOD}$ \\
\hline $\mathrm{F}$ & $0.84 \pm 0.01$ & $0.58 \pm 0.01$ & $<\mathrm{LOD}$ & $<\mathrm{LOD}$ \\
\hline $\mathrm{F}^{*}$ & $3.45 \pm 0.10$ & $0.70 \pm 0.01$ & $<\mathrm{LOD}$ & $<\mathrm{LOD}$ \\
\hline G & $<\mathrm{LOD}$ & $0.45 \pm 0.07$ & $<\mathrm{LOD}$ & $<\mathrm{LOD}$ \\
\hline $\mathrm{G}^{*}$ & $3.11 \pm 0.04$ & $0.47 \pm 0.04$ & $<\mathrm{LOD}$ & $<\mathrm{LOD}$ \\
\hline $\mathrm{H}$ & $0.63 \pm 0.09$ & $0.47 \pm 0.06$ & $<$ LOD & $<$ LOD \\
\hline $\mathrm{H}^{*}$ & $1.20 \pm 0.07$ & $<\mathrm{LOD}$ & $<\mathrm{LOD}$ & $<\mathrm{LOD}$ \\
\hline $\mathrm{J}$ & $0.80 \pm 0.05$ & $0.44 \pm 0.02$ & $0.46 \pm 0.07$ & $0.99 \pm 0.04$ \\
\hline $\mathrm{J}^{*}$ & $0.93 \pm 0.1$ & $<\mathrm{LOD}$ & $<\mathrm{LOD}$ & $<\mathrm{LOD}$ \\
\hline K & $1.15 \pm 0.2$ & $0.3 \pm 0.03$ & $<\mathrm{LOD}$ & $<\mathrm{LOD}$ \\
\hline $\mathrm{K}^{*}$ & $0.77 \pm 0.09$ & $<\mathrm{LOD}$ & $<\mathrm{LOD}$ & $<\mathrm{LOD}$ \\
\hline $\mathrm{L}$ & $1.30 \pm 0.01$ & $3.39 \pm 0.30$ & $<\mathrm{LOD}$ & $<\mathrm{LOD}$ \\
\hline $\mathrm{L}^{*}$ & $0.98 \pm 0.10$ & $<\mathrm{LOD}$ & $<\mathrm{LOD}$ & $<$ LOD \\
\hline M & $1.6 \pm 0.06$ & $<$ LOD & $<\mathrm{LOD}$ & $<\mathrm{LOD}$ \\
\hline$M^{*}$ & $1.25 \pm 0.20$ & $0.38 \pm 0.05$ & $<\mathrm{LOD}$ & $<\mathrm{LOD}$ \\
\hline${ }^{\mathrm{a}} \mathrm{N}$ & $4.2 \pm 0.30$ & $1.98 \pm 0.30$ & $<\mathrm{LOD}$ & $<\mathrm{LOD}$ \\
\hline${ }^{\mathrm{a}} \mathrm{N}^{*}$ & $4.52 \pm 0.05$ & $1.70 \pm 0.20$ & $<\mathrm{LOD}$ & $<\mathrm{LOD}$ \\
\hline \multicolumn{5}{|c|}{ Type dark beer } \\
\hline $\mathrm{O}$ & $1.00 \pm 0.10$ & $0.32 \pm 0.03$ & $<\mathrm{LOD}$ & $<\mathrm{LOD}$ \\
\hline $\mathrm{O}^{*}$ & $1.12 \pm 0.10$ & $0.38 \pm 0.02$ & $<\mathrm{LOD}$ & $<\mathrm{LOD}$ \\
\hline $\mathrm{P}$ & $0.82 \pm 0.02$ & $0.26 \pm 0.01$ & $<\mathrm{LOD}$ & $<\mathrm{LOD}$ \\
\hline $\mathrm{P} *$ & $1.48 \pm 0.10$ & $<\mathrm{LOD}$ & $<\mathrm{LOD}$ & $<\mathrm{LOD}$ \\
\hline Q & $0.9 \pm 0.002$ & $<\mathrm{LOD}$ & $<\mathrm{LOD}$ & $<\mathrm{LOD}$ \\
\hline $\mathrm{Q}^{*}$ & $3.2 \pm 0.25$ & $0.27 \pm 0.15$ & $<\mathrm{LOD}$ & $<\mathrm{LOD}$ \\
\hline
\end{tabular}

${ }^{\mathrm{a}}$ without alcohol. brands. The different types of packaging were considered to determine any correlation between the THM concentrations and packaging. However, any knowledge of different chemical processes being involved in package manufacturing is unknown.

Table 4 shows the results of the analysis of the 32 beers. THMs were found in the samples analyzed, but no sample contained concentrations above that allowed in drinking water by the US EPA. Chloroform was detected in all of the samples except one (sample G). Bromoform was only detected in sample J. Dichlorobromoform and dibromochloroform were not detected in the dark beer samples.

\section{CONCLUSIONS}

We optimized the method parameters for the determination of THMs by gas chromatography and electron capture detection using a univariate design, and successfully analyzed the THMs in 32 beer samples. The proposed method gave excellent detection limits (far below the maximum drinking water limits permitted by regulatory bodies), relative standard deviations, and relative sensitivities. No significant differences were found between the THM concentrations in beers that were supplied in different types of packaging or in the two types of beer analyzed (pilsen and dark). The THM concentrations found in commercially available beer samples were below the concentrations permitted in drinking water by the US EPA.

\section{REFERENCES}

1. CETESB-Companhia de tecnologia de saneamento ambiental. Cervejas e refrigerantes. Serie P+L. São Paulo, 2005.

2. Richardson, S. D.; Simmons, J. E.; Rice, G.; Environ. Sci. Techonol. 2002, 36, 198.

3. Cantor, K. P.; Lynch, C. F.; Hildesheim, M. E.; Dosemeci, M.; Lubin, J.; Alavanja, J.; Craun, G.; Epidemiology 1998, 9, 21.

4. AWWA Research Foundation. Characterization of Natural Organic Matter in Drinking Water by AWWA Research Foundation and American Water Works Association; Croue, J. P; Korshin, G. V.; Benjamin, M. M., eds.; Amer Water Works Assn: Denver, 2000.

5. Blatchley III, E. R.; Margetas, D.; Duggirala, R.; Water Res. 2003, 37, 4385.

6. Rodriguez, M. J.; Sérodes, J. B.; Levallois, P.; Water Res. 2004, 38, 4367.

7. Hsu, C. H.; Jeng, W. L.; Chang, R. M.; Chien, L. C.; Han, B. C.; Environ. Res. 2001, 85, 77.

8. Williams, P.; Bentom, L.; Warmerdam, J.; Sheehans, P.; Environ. Sci. Technol. 2002, 36, 4721.

9. Landi, S.; Naccarati, A.; Ross, M. K.; Hanley, N. M.; Dailey, L.; Devlin, R. B.; Vasquez, M.; Pegram, R. A.; De Marini, D. M.; Mutat. Res. 2003, $538,41$.

10. Environmental Protection Agency. Disinfectants, disinfection byproducts, final rule-National Primary Drinking Water Regulations. Federal Register, December 16, 1998.

11. Richardson, S. D.; Trends Anal. Chem. 2003, 22, 666.

12. Golfinopoulos, S. K.; Nikolaou, A. D.; Desalination 2005, 176, 13.

13. Batterman, S.; Zhang, L.; Wang, S.; Franzblau, A.; Sci. Total Environ. 2002, 284, 237.

14. Environmental Protection Agency. Control of organic chemical contaminants in drinkingwater-interim primary drinking water regulations. Federal Register, February 9, 1978.

15. Anand, S. S.; Philip, B. K.; Palkar, P. S.; Mumtaz, M. M.; Latendresse, J. R.; Mehendale, H. M.; Toxicol. Appl. Pharmacol. 2006, 213, 267.

16. Environmental Protection Agency. Toxicological Review of Chloroform. EPA/635/R-01/001 Washington, DC, 2002. 
17. Hsu, H. T.; Chen, M. J.; Lin, C.H.; Chou, W. S.; Chen, J. H.; Water Res. 2009, 43, 3693.

18. DeAngelo, A. B.; Geter, D. R.; Rosember, D. W.; Crary, C. K.; George, M. H.; Cancer Lett. 2002, 187, 25.

19. Ross, M. K.; Pegram, R. A.; Toxicol. Appl. Pharmacol. 2004, 195, 166.

20. Kuran, P.; Sojak, L.; J. Chromatogr. A 1996, 733, 119.

21. Van Langenhove, D. H. J.; J. Chromatogr. A 1999, 843, 163.

22. Allonier, A. S.; Khalanski, M.; Bermond, A.; Camel, V.; Talanta 2000, $51,467$.

23. Bahri, M.; Driss, M. R.; Desalination 2010, 1, 414.

24. Pawliszyn, J.; Trends Anal. Chem. 1995, 14, 113.

25. Mallia, S.; Fernandez-Garcia, E.; Bosset, J. O.; Int. Dairy J. 2005, 15, 741.

26. Povolo, M.; Contarini, G.; J. Chromatogr. A 2003, 985, 117.

27. Zoccolillo, L.; Amendeola, L.; Cafaro, C.; Insogna, S.; J. Chromatogr. A 2005, 1077, 181.
28. Dos Santos, M. S.; Martendal, E.; Carasek, E.; Food Chem. 2011, 127, 290.

29. Stack, M. A.; Fitzgerald, G.; O'Connell, S.; James, K. J.; Chemosphere 2000, 41, 1821

30. Cancho, B.; Ventura, F.; Galceran, M. T.; J. Chromatogr. A 2010, 943, 1.

31. San Juan, P. M.; Carrillo, J. D.; Tena, M. T.; J. Chromatogr. A 2007, 1139, 27.

32. Lara-Gonzalo, A.; Sánchez-Uría, J. E.; Segovia-García, E.; Sanz-Medel, A.; Talanta 2008, 74, 1455.

33. O’Reilly, J.; Setkova, L.; Hutchinson, J. P.; Chen, Y.; Lord, H. L.; Linton, C. M.; Pawliszyn, J.; J. Sep. Sci. 2005, 28, 2010

34. Antoniou, C. V.; Koukouraki, E. E.; Diamadopolus. E.; J. Chromatogr. A 2006, 1131, 310.

35. Nakamura, S.; Daishima, S.; Anal. Chim. Acta 2005, 548, 79.

36. Cho, D. K.; Kong, S. H.; Oh, S. G.; Water Res. 2003, 37, 402. 